C. \& V., without good reason, since G. flarus is described as having "la bouche fendue jusque sous l'arrière de l'œil," whereas in $G$. latus the cleft of the mouth barely extends to below the middle of the eye. Moreover, it appears to me to be unjustifiable to place $G$. banana, C. \& V., in the synonymy of $G$. taiasica, Lichtenstein. The description of this latter species is entirely inadequate, but as it is said to come from Brazil it is more probably identical with $G$. latus than with $G$. banana, which has been recorded from the Antilles and frorn Central America.

\title{
Chasmodes maculipinna.
}

Depth of body 4 times in the total length, length of head $3 \frac{1}{5}$ times. Snout concave, equal in length to the eye, the diameter of which is $4 \frac{1}{4}$ times in the length of head. Interorbital space narrow, concave. Maxillary extending to below posterior $\frac{1}{3}$ of eye. D. XII 14, a notch between spinous and soft-rayed portions, the latter the higher, its longest rays equal to the postorbital part of head. A.18. Pectoral equal to 3 the length of head. Anterior part of dorsal with a large black spot, extending from the first to the fourth spine.

Total length $63 \mathrm{~mm}$.

A single specimen from the Rio Durango, N.W. Ecuador.

LXV.-Notes on Scapholeberis aurita (S. Fischer), a Cladoceran new to Britain. By Robert Gurney, B.A., Sutton Broad Laboratory.

THE only species of the genus Scapholeberis hitherto recorded as British is S. mucronata (O. F. Müller), but I have now to add $S$. aurita, which I have recently found in three localities in Norfolk. Considering the peculiar swimming habits of S. mucronata, as described by $\mathrm{Mr}$. Scourfield *, it may be of interest to compare the two species in this respect, and also with regard to certain points in their structure.

In both species the ventral margin of the shell-valves is flattened, but this area is proportionally larger in S. aurita and is bounded externally by a very prominent ridge and internally by the thickened edge of the valve. This thickening of the edge, which is quite conspicuous, is not continued the

* Journ. Linn. Soc., Zool. vol. xxy. pp. 1-19 (1894). 
whole length of the valve, but near the anterior end is continuous with an obliquely transverse ridge which joins the external ridge (fig. 1). There is thus marked off in front a

Fig. 1.

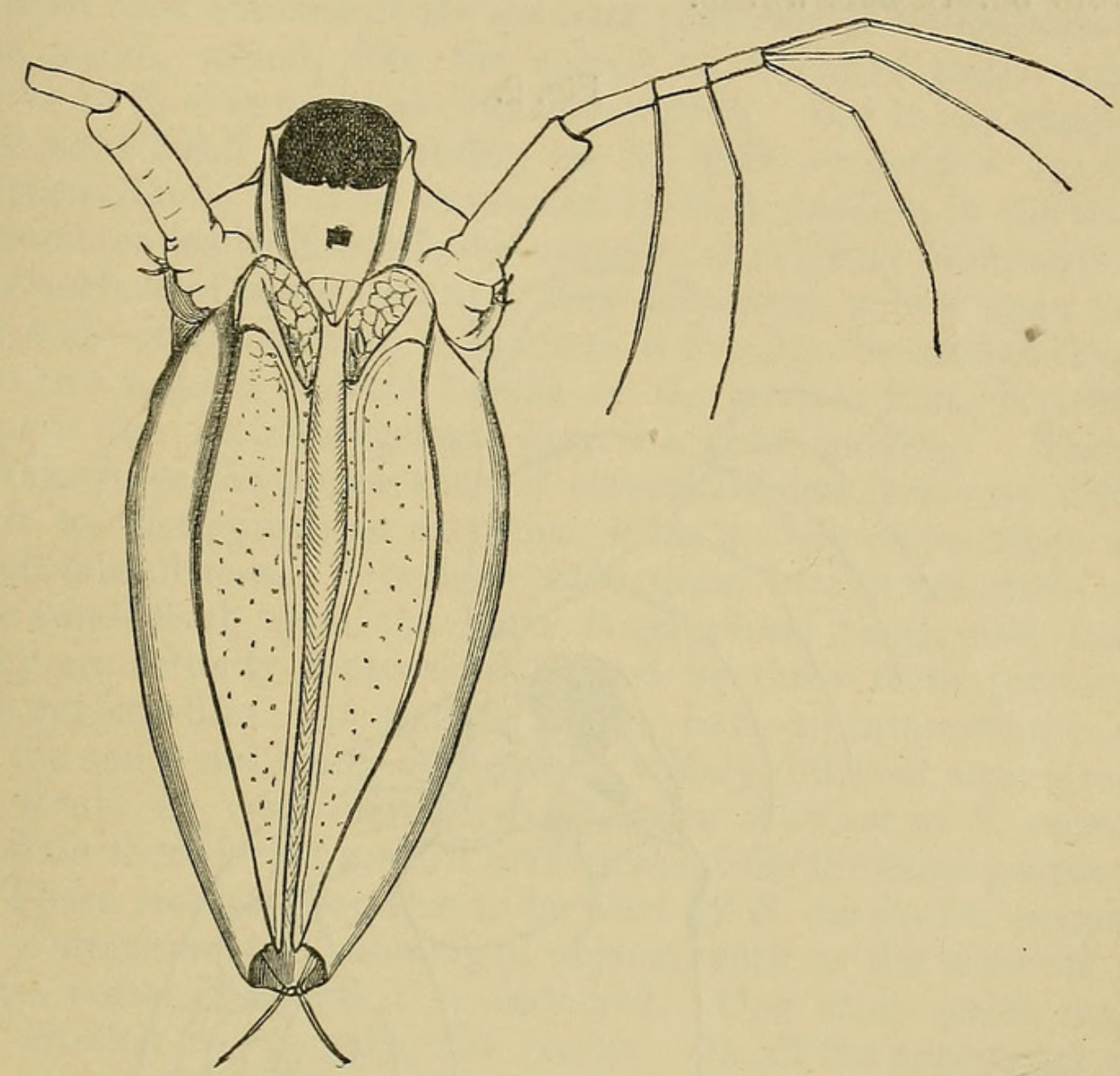

more or less triangular area which is somewhat depressed and strongly reticulate. The remaining portion of the valves in S. aurita is not reticulate, but simply punctate.

Seen from the side (fig. 2) the shell-margin is almost straight, but with a prominent projection anteriorly corresponding to the point of union of the transverse and external longitudinal ridges.

So far the two species are in essential agreement, but they differ strikingly in the armature of the flattened area. In S. mucronata this area is provided with a number of peculiarly arranged scales and modified setæ (see Scourfield, pl. ii. fig. 1), but nothing of the kind occurs in S. aurita. Here the flattened area shows no setæ whatever, and the setæ which fringe the inner edge of the valves are quite simple and delicate. On the other hand, careful examination of the inner longitudinal thickening shows a series of small upwardly 
projecting teeth, indicated in fig. 1 . There may be from five to eight of these teeth, the first (which is the largest) placed just at the junction of the transverse and inner longitudinal ridges, and the remainder along the latter to a point about halfway along the shell. They increase somewhat in size from before backwards.

Fig. 2.

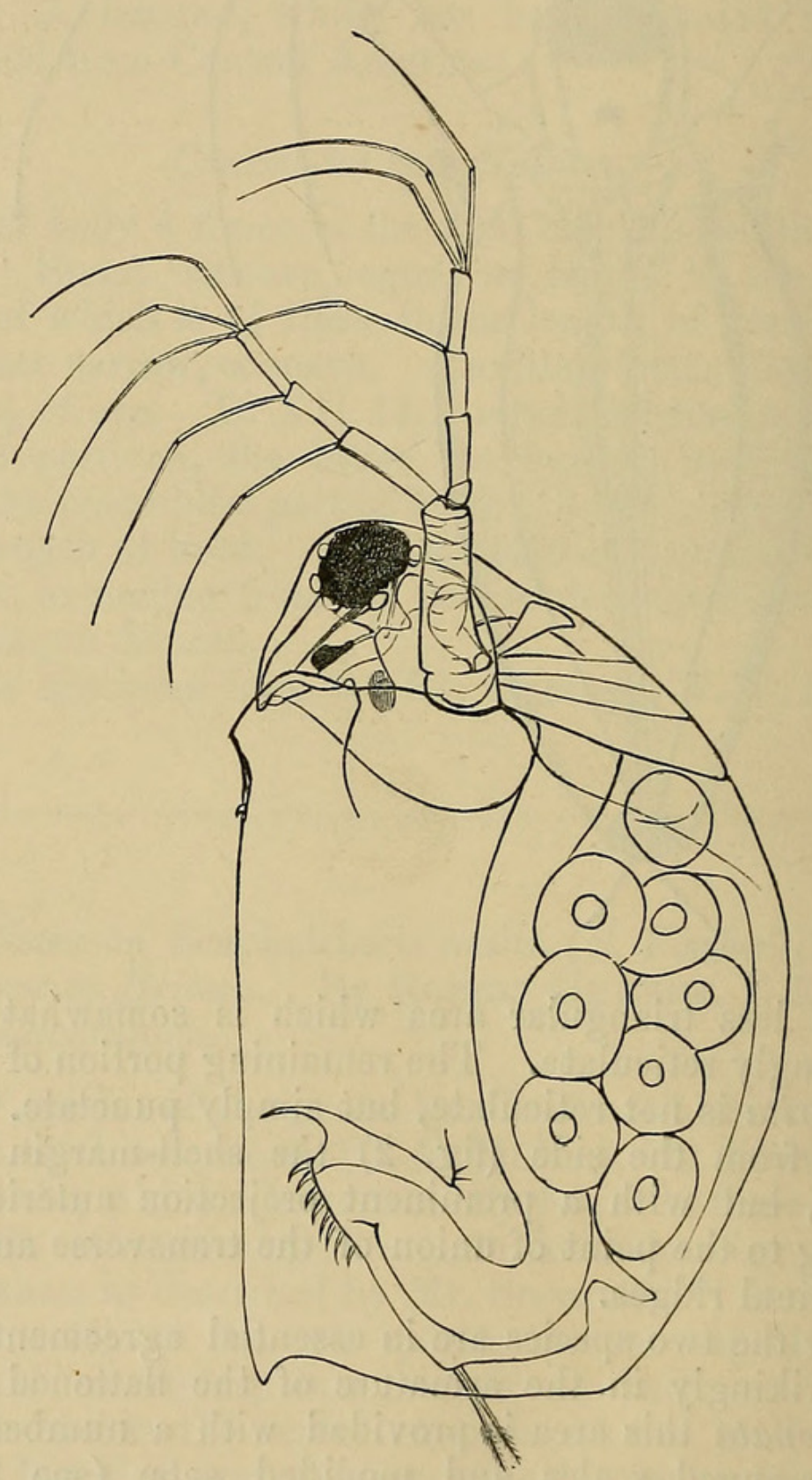

Now it has been shown by Scourfield that it is by means of the modified setæ of its flattened shell-margin that S. mucronata supports itself from the surface-film, and it might be supposed that $S$. aurita, lacking these setæ, would 
not have the same habit. It does indeed differ in some respects from its relative, being much less active in its movements, and also it does not always, as Lilljeborg * has already pointed out, swim upon its back. In fact its movements are somewhat aimless, and it seems likely that this is due to the almost total absence of the spinous posterior prolongations of the valve, which, like the spines of Decapod zoëas, may serve in S. mucronata as directive organs. But it has exactly the same habit of swimming on its back suspended by the surface-film. If it is examined in this position in the way recommended by Scourfield-namely, by brightly illuminating the surface of the water, and then focussing a lens upon the animal-it can be seen that where it touches the surface there are two rows of minute breaks in the surface-film, between which the swimming-legs may be seen moving. These breaks have the appearance of elevations, but it is very difficult to distinguish an elevation from a depression when of such minuteness. I believe that these breaks are made by the small teeth upon the inner longitudinal ridge, and that they are actually depressions caused by these teeth piercing the surface-film. If that is so, we have an interesting case of the same end being attained by widely different structures. It would be very instructive to know whether in S. microcephala there is yet a third arrangement for the same purpose.

These teeth appear also to be used by $S$. aurita for temporary attachment to submerged objects, such as the sides of a glass vessel in which it is contained. One other point may be alluded to, namely, the colour. In all the specimens of $S$. aurita which I have seen the colour is more or less deep orange, though it varies greatly according to Lilljeborg. There is no localized distribution of the pigment about the ventral surface such as obtains in $S$. mucronata and has been explained as a protective modification.

\section{LXVI.-Three new Bats from the Cameroons, discovered by} Mr. G. L. Bates. By Oldfield 'l'homas.

\section{Nycteris arge, sp. $\mathrm{n}$.}

Allied to $N$. thebaica, but with much smaller tragus.

Size medium. General colour dark brownish above and below. Nose-leaf of normal structure, but unusually thickly

$$
\text { * 'Cladocera Suecix,' 1900, p. } 164 .
$$




\section{$2 \mathrm{BHL}$ Biodiversity Heritage Library}

Gurney, Robert. 1903. "LXV.-Notes on Scapholeberis aurita (S. Fischer), a cladoceran new to Britain." The Annals and magazine of natural history; zoology, botany, and geology 12, 630-633.

https://doi.org/10.1080/00222930309487044.

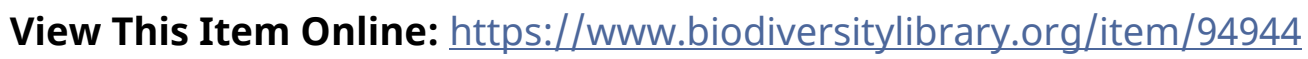

DOI: https://doi.org/10.1080/00222930309487044

Permalink: https://www.biodiversitylibrary.org/partpdf/68445

\section{Holding Institution}

Harvard University, Museum of Comparative Zoology, Ernst Mayr Library

\section{Sponsored by}

Harvard University, Museum of Comparative Zoology, Ernst Mayr Library

\section{Copyright \& Reuse}

Copyright Status: Public domain. The BHL considers that this work is no longer under copyright protection.

This document was created from content at the Biodiversity Heritage Library, the world's largest open access digital library for biodiversity literature and archives. Visit BHL at https://www.biodiversitylibrary.org. 